of use to many authorities who to-day are faced with the problem of improving water supplies. The extension of the electricity grid will naturally lead to the installation of electrical pumping plant in preference to steam and oil-driven plant on account of the possibility of automatic control. Many facts and figures as to cost and maintenance of plants and examples of installations are given, ranging from those suitable for a single house to those for large rural areas. In one district with a population of 17,000 spread over an area of 23,000 acres, a scheme was carried out for supplying $12 \frac{1}{2}$ gall. per head, the charge for which was approximately two shillings in the pound on the net annual value of the premises. The amount of water used will, of course, depend largely on the sewage system, but it is generally accepted that 25 gall. per head is a safe figure in planning a rural scheme.

\section{Guide Books and Museums}

Two guides to the palæontological collections of the British Museum (Natural History) have recently been issued. One of them, the "Guide to the Fossil Birds, Reptiles and Amphibians", claims to be "rather the first edition of a new Guide than a new edition of the old", while the other, the "Guide to the Fossil Mammals", is a reprint "altered and corrected where necessary" (London: British Museum (Natural History), 1s. each). Both guides call for criticism. In the first place it is a little difficult to know to what class of reader they are addressed. If for the serious student of palæontology, they are not sufficiently full and contain some rather serious errors, while to the visitor who only wishes to take an intelligent interest and have a little of the veil lifted, they are likely to be wellnigh unintelligible. This difficulty might perhaps be overcome by the use of material already to hand. In 1923 there was published a guide to the exhibition galleries of geology and palæontology, which, rewritten if necessary and with a few well-chosen illustrations, would serve the general public admirably and might be of use to the more elementary of the students. It may also be suggested that a series of separate guides, or guide leaflets, such as are to be found issued by the American Museum of Natural History, would serve a useful purpose. In fact, this plan is already partially in operation in the Natural History Museum. There is a "Guide to the Fossil Remains of Man", published in 1915 at a price of fourpence and a guide to the "Elephants (Recent and Fossil)" published as a second edition in 1922 for a shilling, both very satisfactory. Detailed criticism of the two guides under notice is out of place here, but it may be remarked that neither gives a clear idea of the evolution or classification of groups, while the purpose of some of the illustrations is obscure. It is to be hoped that the authorities will consider not a republication from time to time of matter which has served its purpose and has in course of time become obsolete, but an entire replanning and rewriting of guides to the national collections to meet the two distinct calls made on them, by the student and by the general public.

\section{Average Temperatures in the British Isles}

THE number of persons requiring information about the temperature normally experienced in different parts of the British Isles, for one purpose or another, has for many years been large enough to make it an important part of the work of the Meteorological Office to secure so far as possible that standard methods of obtaining air temperature shall be followed both at official and private meteorological stations, and that summaries of these records in comparable form shall be available for inquirers. In a recent handbook ("Averages of Temperatures for the British Isles." H.M. Stationery Office. 9d., postage extra) monthly and annual averages of the daily maximum and minimum temperature are given, so far as possible, for the years 1901-1930. As there are, however, many stations for which the averages can refer to only a portion of that period, the inquirer has to be warned against indiscriminate comparisons; for example, differences between a pair of stations for which the period of years referred to is not the same may be due more to peculiarities of the two periods than to real climatic differences ; there is the further pitfall of possible differences in times of setting of the maximum and minimum thermometers at the two places. These matters are dealt with in the introduction and the necessary information is shown against each set of figures. It may be observed that the precise meaning of the 'normal' or 'average' maximum or minimum temperature for a given season and a given place is not easily defined. In Table I of the "Book of Normals", which the tables under review supersede, the mean temperature at Kew in January (or rather the mid-point between the mean daily maximum and mean daily minimum) is given as $38.9^{\circ} \mathrm{F}$., whereas in the new tables it appears as $40 \cdot 4^{\circ} \mathrm{F}$. The relatively low figure in the "Book of Normals" is due partly to the fact that in the period covered therein (1881-1915) there was a notable run of cold winters, those of the early 'nineties, while the winters of 1901-30 have mostly been mild; there is no means of knowing whether the next 30 years will give an average or 'normal' near to $38 \cdot 9^{\circ} \mathrm{F}$. or one nearer to $40 \cdot 4^{\circ}$.

\section{British Empire Broadcasting}

Some of the difficulties overcome by the British Broadcasting Corporation in establishing a broadcast service between Great Britain and distant regions of the Empire are well described in a paper in Electrical Communication of April by C. M. Benham and P. H. Spagnoletti. Except in special cases, long distance radio communication is practical only when short wave-lengths are used. It was necessary therefore to use radio equipment of the short wave type. Fortunately, the colonies and dominions are so distributed longitudinally that they can be conveniently divided into time zones, that is, areas which have approximately the same local time. There are four main zones: Australia, which has a time displacement relative to London of 'eight hours early'; India, 'four hours early'; Africa, the same time; and Canada, 'six hours late'. In the case 
of Australia, the farthest away, transmission must travel through twilight conditions whichever path round the world is used. It was not expected therefore that wave-lengths of 15 metres, using the daylight path, or 37 metres using the dark path, would give trustworthy service. Both can be used for short periods but their useful duration is limited and uncertain. The twilight band (25-29 metres) has been found to be the best. In the Indian zone it has been found that 17 metre transmissions are very satisfactory. In the case of Africa, as it lies almost due south, shorter wave-lengths are used during the day, intermediate wave-lengths at dusk and at nighttime 32 metre wave-lengths or even longer can be used. It is found better to divide Africa into two zones. The great circle path to Canada passes very near to the north pole and even in summer it is not a true daylight path. A satisfactory day wave for Canada is of the order of 19 metres, but night waves of 31 and 50 and sometimes as high as 70 or 80 metres have been used. The B.B.C. deserves great credit for having overeome so successfully many of the difficulties connected with the most ambitious project ever attempted in broadcasting.

\section{Standardisation of Electricity Supply}

IN a paper read on May 31 to a meeting of the Incorporated Municipal Electrical Assuciation (the I.M.E.A.), which was held in Liverpool, L. Romero discussed the standardisation of methods for distributing electricity and for its sale. He recently addressed a questionnaire to sixty of the largest municipal supply undertakings in Great Britain, and nearly all had replied explaining the systems they used and in particular the voltages which they adopted to supply their consumers. It was decided officially some years ago that the standard system of supply should be the alternating current system and that the standard pressure for domestic supply should be 230 volts. The replies received show that about a third of the municipal undertakings are maintaining voltages which are not standard and that the number of consumers using these voltages is rapidly increasing. The reason given for not adopting the standard is that the change would be expensive. This is a short-sighted policy, as it causes expense to consumers and is a definite obstacle in the way of cheapening electrical lamps and appliances. Several countries abroad also suffer from this lack of standardisation. Luckily, in Great Britain, the progress made in changing from D.C. to A.C. supply is much more satisfactory. Many people think that the supply of electricity should be managed on a national basis, their principal argument being the lack of standardisation that otherwise ensues. Presumably local authorities desire to manage their own electricity supply. Some of them would therefore do well to regard standardisation from a broader point of view.

\section{Electrification of Collieries}

ALtнобан great progress has been made during recent years in the electrification of collieries, about one third of the total power utilised is still generated mechanically. According to the Electrical Review of June 29, the total horse-power of the motors in use in collieries is now about $1,900,000$. This is equivalent to more than ten per cent of the capacity of all the plant connected to the public supply mains in Great Britain. Of the electricity used, only about thirty per cent is supplied by statutory authorities. Doubtless this percentage will rapidly increase, as power can be produced more cheaply at points away from the pithead where a more abundant water supply is available for condensing purposes. It is satisfactory to notice that, despite the increase in the use of electricity, the number of electrical accidents is steadily decreasing. This is due to the design of flame-proof structures and flame-proof apparatus. Owing to the high standards adopted by the Association of Mining Engineers, the costs of maintenance have also rapidly diminished. The fixing of minimum standards for illumination for portable lamps is a notable advance. We think that inventors ought to turn their attention to the development of a fixed lighting system which would be safe to use at all parts of the coal face.

\section{Interference with Radio Supply by Electric Lighting}

IT is well known that when direct current supply is used for electric lighting, the contacts of the switches and fuses often get badly corroded after a few years' operation. This usually causes little, if any, inconvenience in the lighting of the house or in the use of electric appliances, but if a radio receiver be installed the loud speaker produces most unpleasant noises. This is often attributed quite wrongly to some fault in the set. In many cases the noises are got rid of by having the electric wiring overhauled. According to a paper in the Electrical Review of June 1 by V. Z. de Ferranti, many domestic electrical appliances also cause bad radio reception. As examples he gives electric bells operated from the mains, children's electric toy trains, a bad contact in an electric fire and, worst of all, any piece of equip ment driven by a motor. He points out that it is far easier to supply equipment which can be trusted to cause no interference than to eliminate by special devices the interference caused by equipment already installed. The special devices are often expensive. He estimates that there are now two and a half million mains-operated radio sets in Great Britain. Collectively, they take about 150,000 kilowatts and the average demand is about two hours a day. In addition, the demand for this load is outside the busy hour of supply and it is therefore desirable to the electricity companies. There is quite an appreciable number of small house-holders who have availed themselves of electric supply primarily in order to be able to use it for radio receiving sets.

\section{Secret Radio-telephony}

A ScIence Service Mail Report dated May 28 states that Dr. S. Chiba, of the Tokyo Electric Co., has developed a secret method of radio-telephonic communication. According to the description, the 